\title{
Advanced research on deep brain stimulation in treating mental disorders (Review)
}

\author{
DONGXIN WANG $^{1 *}$, XUEJUN LIU ${ }^{1}$, BIN ZHOU ${ }^{2}$, WEIPING KUANG $^{2}$ and TIANSHENG GUO ${ }^{*}$ \\ ${ }^{1}$ Mental Health Institute of Hunan Province; ${ }^{2}$ Surgery Department of Mental Disease, \\ The Brain Hospital of Hunan Province, Changsha, Hunan 410007, P.R. China
}

Received September 9, 2015; Accepted July 10, 2017

DOI: $10.3892 /$ etm.2017.5366

\begin{abstract}
Deep brain stimulation is a method that involves using an electric stimulus on a specific target in the brain with stereotaxis. It is a minimally invasive, safe, adjustable and reversible nerve involvement technology. At present, this technique is widely applied to treat movement disorders and has produced promising effects on mental symptoms, including combined anxiety and depression. Deep brain stimulation has therefore been employed as a novel treatment for depression, obsessive-compulsive disorder, habituation, Tourette's syndrome, presenile dementia, anorexia nervosa and other refractory mental illnesses. Many encouraging results have been reported. The aim of the present review was to briefly describe the mechanisms, target selection, side effects, ethical arguments and risks associated with deep brain stimulation. Although deep brain stimulation is a developing and promising treatment, a large amount of research is still required to determine its curative effect, and the selection of patients and targets must be subjected to strict ethical standards.
\end{abstract}

\section{Contents}

1. Introduction

2. Mechanisms of DBS

3. The selection of different targets for DBS in treating mental diseases

4. The side effects of DBS

5. Discussion

Correspondence to: Dr Tiansheng Guo or Dr Dongxin Wang, Mental Health Institute of Hunan Province, The Brain Hospital of Hunan Province, Section 3, Furong Middle Road, Dongcheng, Changsha, Hunan 410007, P.R. China

E-mail: guotiansheng00000@yeah.net

E-mail: 46677076@qq.com

*Contributed equally

Key words: deep brain stimulation, mental disorder, psychotherapy, target, treatment

\section{Introduction}

Electric shock treatment (EST) is a psychotherapy that may be used alone or in combination with drug therapy, and has demonstrated positive curative effects in the treatment of mental disorders $(1,2)$ However, there are a considerable number of patients, known as 'refractory' patients, who are immune to these clinical interventions and show little possibility of recovery (3). Refractory mental illnesses contribute greatly to disability worldwide; therefore identifying effective alternative therapies may make a huge difference for such patients.

Deep brain stimulation (DBS) is accomplished via a nerve stimulator implanted in the body and supplied by a battery source, commonly known as a brain pacemaker (4). Typically, a pulse generator supplied with a lithium battery is placed under the skin in the chest area, with one or two wires attaching it to an implanted electrode that is oriented to the target region for brain stimulation (inserted using the stereotactic technique) (5). The pulse stimulation is conducted from the generator to the electrode in the location of interest in the deep brain (Fig. 1) (6). DBS has been used as a treatment for mental diseases since 1987 (7). DBS as a treatment for chronic diseases was first employed by Benabid et al to treat dyskinesia (7) and at present, is primarily used to treat tremors caused by Parkinson's disease, chronic pain and dysmyotonia. Attempts have been made to develop its use in the treatment of mental disorders (8).

The first mention of using DBS to treat mental diseases in literature was in a report published in the Lancet journal in 2002 discussing the therapy as a possible treatment for obsessive-compulsive disorder (OCD) and transient tic disorder (8). The first report suggesting that DBS could treat depressive disorder was published in 2005 (9). DBS has been authorized for the treatment of epilepsy and OCD in Europe, and for the treatment of refractory OCD treatment in the USA (10). This approval has increased research and promoted the development of DBS, particularly regarding the mechanisms of vagus nerve stimulation (11).

Side effects are uncommon following treatment with DBS, and only mild side effects have been observed when it is used as a treatment for dyskinesia (12). This highlights the advantages of DBS technology; it has good specificity, and the inhibitory effect of deep brain stimulation on the motor nucleus of the thalamus disappeared after the cessation of stimulation (13). 
Such advantages are particularly important considering that at present, there are no effective therapies available to treat the majority of mentally handicapped individuals. To treat conditions where it is unknown whether the therapy will have beneficial effects, the moral compulsory principle of 'no harm' makes DBS an attractive option. Unlike neurosurgical treatments, DBS is fully reversible, providing the potential means to identify therapeutic targets for the treatment of mentally handicapped individuals without risking permanent damage (Fig. 2) (14).

The current review summarizes the selection and relative benefits of different therapeutic targets of DBS therapy, including refractory depression, OCD, habituation, Tourette's syndrome (TS), anorexia nervosa (AN) and Alzheimer's disease.

\section{Mechanisms of DBS}

The neurobiological mechanisms by which DBS regulates brain function are not yet fully understood (15). The effect of DBS on the cerebral nuclei target region is either excitatory or inhibitory, depending on the properties of internuncial neurons and the afferent neurons in the target region (16). It has been proposed that high-frequency DBS may induce functional damage to areas surrounding the lesion, including closure of current-dependent ion channels (17) and blocking of depolarization via exhaustion of the neurotransmitter (18). The mechanism by which this damage occurs is synapse inhibition and it is also known as neural activation in the stimulated region $(19,20)$.

Many scholars conclude that the influence of DBS on the neurological network is more complicated than simply damaged surgery and that DBS therapy may affect the neuronal somas and the two-way activation function of axons $(21,22)$. Previous studies have reported that various neurotransmitters, including glutamic acid and dopamine, are released following DBS $(23,24)$. Functional neuroimaging data also indicate that DBS alters the brain activity beyond the target area to a large extent, suggesting that DBS may have a sophisticated neural network control function (9,25-27). Benabid et al (7) suggested that DBS therapy may exert synthetic action involving a variety of mechanisms.

\section{The selection of different targets for DBS in treating mental diseases}

The foundation of DBS research involves searching for the target region by theoretical derivation (28). The target chosen by theoretical derivation in mental disease therapy is derived from clinical experience, results from brain imaging and the pathophysiological knowledge of various diseases (29). Mental diseases typically do not result from simple pathological changes in a single brain structure, it is thought that certain brain structures may serve different roles in the progression of disease and its relative symptoms. Targets with similar anatomical structures or functional relationships (neural networks) may generate a superposition effect; therefore, different targets may be able to regulate the same pathological network on different nodes (30). It has been determined that the targets discussed below are able to remit psychosis symptoms (Fig. 3) (6).

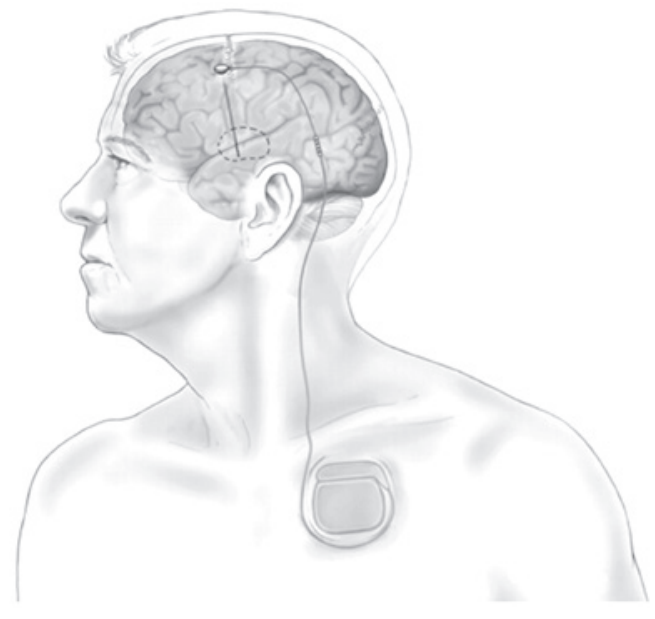

Figure 1. System diagram of deep brain stimulation. The stimulating electrode is implanted by stereotactic neurosurgery and connected to a subcutaneous pulse generator with a wire. This image is provided by David Peace from the Neurosurgery Department, School of Medicine, University of Florida. This image was adapted with permission from Holtzheimer and Mayberg (6).

Depression targets. DBS technology has been used to stimulate Brodmann region cg25 under the cingulate cortex, which serves a pivotal role in regulating negative emotions (9). It has been demonstrated that stimulating this region may have an antidepressant effect (9). Lozano et al (31) demonstrated that it had 55\% efficacy, with a follow-up record of 20 patients who underwent the surgery 3-6 years prior. In another group of patients with depression, the anterior limb of the internal capsule was regarded as the target of DBS therapy (32). One month post-surgery, the depressive symptoms of patients remitted were evaluated using the Montgomery-Asberg Depression Rating Scale (MADRS) (33). This result remained stable as indicated by the rates $(53 \%$ after 12 months and $71 \%$ at last follow-up which ranged from 14 to 67 months). The response criterion indicated a minimum of $50 \%$ reduction in MADRS in this study; however, some patients experienced motor fluctuations for $>6$ months (30).

The nucleus accumbens septi (NAcc) is the DBS treatment target for depression and is able to effectively improve the core symptom of depression, (loss of interest in daily activities), due to the effects of the NAcc on the reward system (14). Bewernick et al (32) followed up 11 NAcc-DBS patients for 4 years and 5 patients $(45 \%)$ experienced lasting beneficial effects.

The ventral capsula interna/ventral striatum (VC/VS) are also regarded as targets for the treatment of depression and may be associated with the regulation of the reward system neural network (34). Malone et al (35) reported that 15 patients with chronic, serious, refractory depression were treated with DBS on the VC/VS and that $40 \%$ of these patients reported positive curative effects 6 months post-surgery.

Other potential functional targets of depression were identified on the basis of animal models and neuroimaging research. Sartorius and Henn (36) first proposed the habenula as a target of DBS in the treatment of depression. This region controls the serotonin-activating nerve fibers dominating the nucleus raphes dorsalis and noradrenergic nerve governing the nucleus ceruleus (37). Sartorius and Henn (36) infer that 

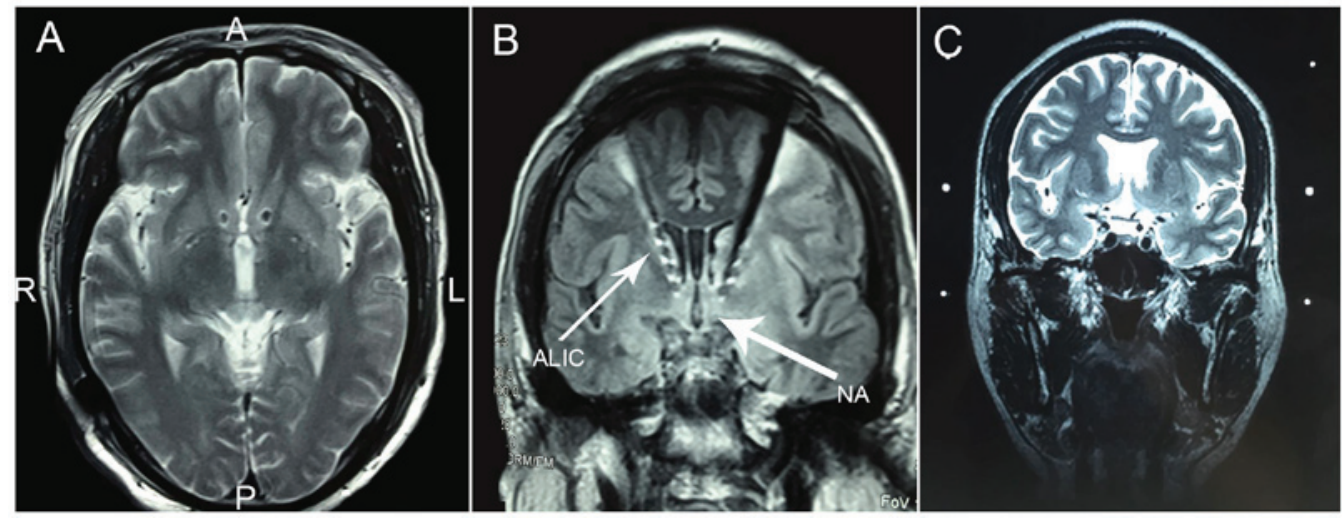

Figure 2. (A) Actual position of the electrode in postoperative X-ray images captured during deep brain stimulation for the treatment of depression. L, left; R, right; A, anterior; P, posterior. (B and C) Path of electrode implantation. ALIC, anterior limb of internal capsule; NA, nucleus accumbens.

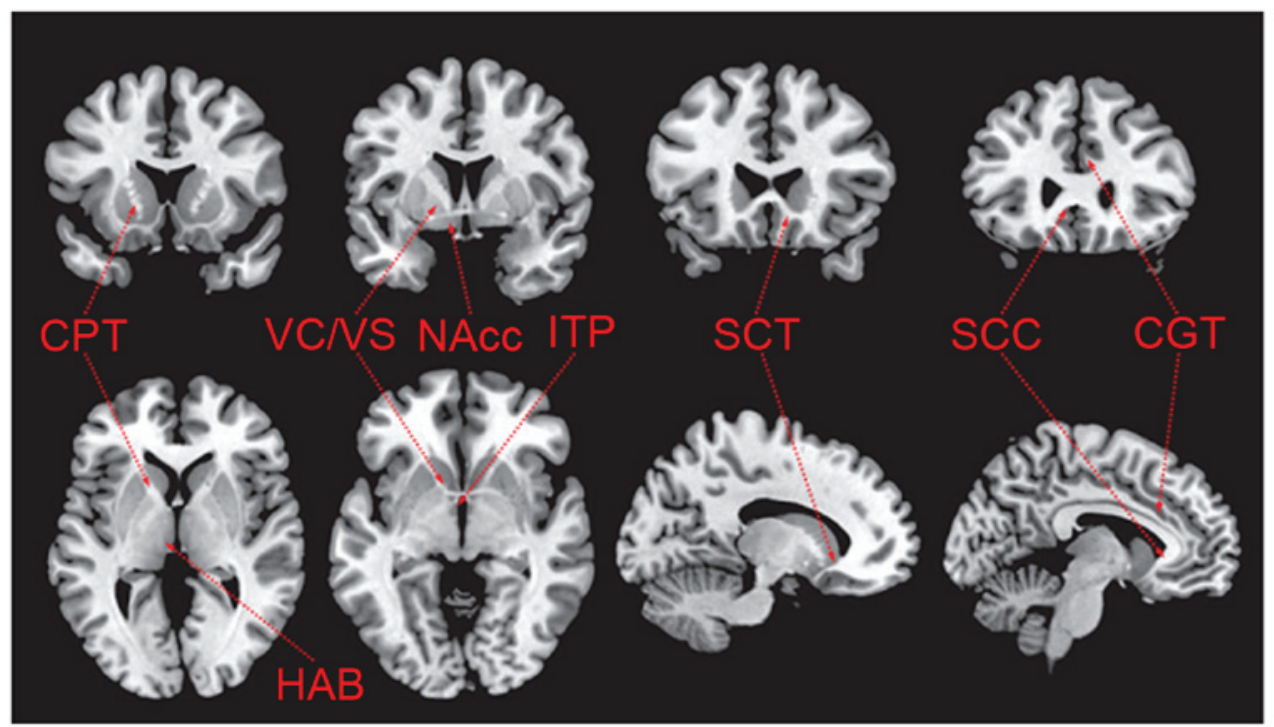

Figure 3. Anatomical targets of deep brain stimulation for the treatment of mental diseases. CPT, capsulotomy; NAcc, nucleus accumbens; SCT, subcaudate tractotomy; VC/VS, ventral capsula interna/ventral striatum; HAB, habenula; SCC, subcallosal cingulate; ITP, inferior thalamic peduncle; CGT, cingulotomy. This image was adapted with permission from Holtzheimer and Mayberg (6).

excessive activation of the habenula nucleus is associated with depression, and the lower part of the thalamus neck connects the non-specific thalamic system and the orbitofrontal cortex. The dysfunction of the non-specific thalamic system appears to serve an important role in the development of depression (36). Stimulating the lower part of the bilateral thalamus neck may also remit depression Hamilton Depression Rating Scale (38) grade decreases from 42 to 10 ) and the positive curative effect is maintained for up to 24 months (36). The use of the blinding method (39) to interrupt the stimulus results in a deterioration of the patient's condition. These targets of depression have only been discussed in case reports so far and require further validation in clinical trials.

Overall, DBS targets for the treatment of depression are being developed continuously. The most effective targets are yet to be identified due to the relatively small sample size that exists at present. However, studies have identified a number of DBS targets that have a persistent anti-depressive effect including the epiphysis frenum, NAcc and the VC/VS (Table I) $(9,32,34-36,39,40)$.
Targets of DBS for OCD. OCD has various targets, as the orbital frontal cortex and anterior cingulate cortex are both part of the OCD circuit. Unfortunately, these regions are very large; thus the size of cortex region that needs to be modulated would be too large $(39,41)$. The majority of studies suggested that unilateral or bilateral stimulation of the anterior limb of the internal capsule as the target, and these studies have reported promising results, from partial amelioration to complete remission (42-47). In terms of side effects, several researchers identified that hypomania, which may occur with direct stimulation, disappeared completely following a decrease in stimulation strength $(41,45,46)$. The acies thalamus optic-zona incerta has also been investigated in three patients with Parkinson's disease and OCD, and the corresponding reports indicate an improvement in obsessive-compulsive symptoms $(8,48)$. One patient with OCD and comorbid depression entered remission following DBS treatment targeting the NAcc and the caudate nucleus $(8,49)$. A total of 14 electrode-implanted patients reported highly therapeutic effects following unilateral stimulation of the NAcc 


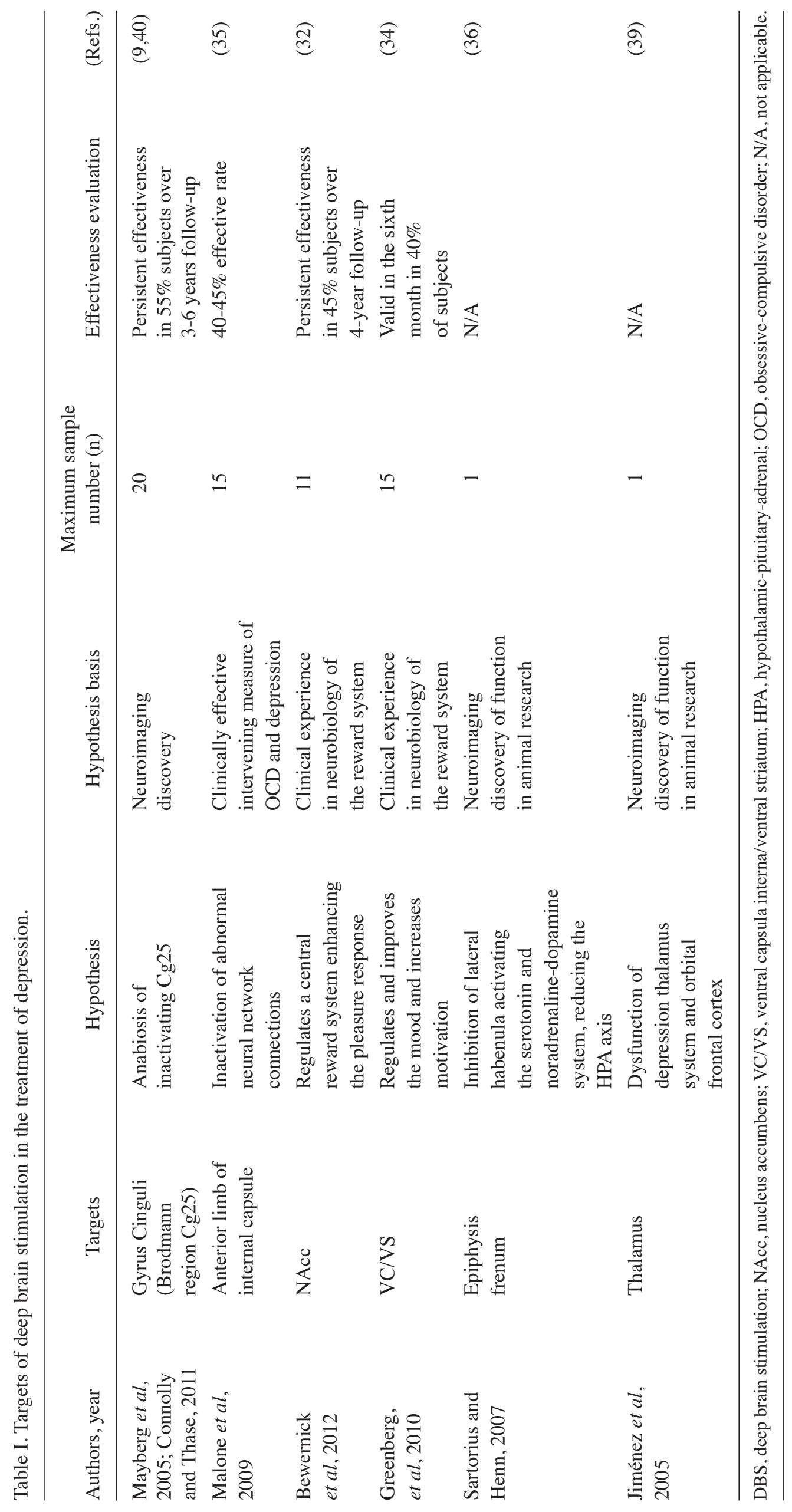


and VC/VS stimulation improved the condition of $50 \%$ of patients (41). Side effects, including transient hypomania and anxiety induced by DBS treatment, are typically eliminated by changing the parameters, including stimulus frequency, pulse widths, stimulus duration and voltage (Table II) $(34,49-52)$.

Various targets of DBS for the treatment of OCD have been verified with encouraging results; however identifying a universal satisfactory target is not yet possible due to small sample sizes. Furthermore, OCD is a heterogeneous disease and patients with different symptom groups may have different ideal targets.

Targets of DBS habituation. The application of DBS to treat habituation was reported in a previous case report (15). Studies involving animal models and imaging research are able to further increase understanding regarding the mechanisms and safety of the treatment. Previous studies have reported that there may be a specific ideal target of DBS treatment for habituation (Table III) (53-57). However, it should be noted that the potential targets are not mutually independent and selection of the ideal target requires more support from clinical and research data due to potentially overlapping mechanisms and functions. It is worth noting that the NAcc may be identified as the ideal target for DBS treatment in patients with refractory habituation. A total of 5 clinical studies involving 18 patients have already identified curative effects with no reported side effects (24,57-60). A meta-analysis indicated that the success rate of DBS in the treatment of drug addiction is up to $49 \%$ (61).

Targets of TS. TS is a neuropsychological disease characterized by phonation spasm and motion spasm, with a $1 \%$ prevalence rate (62). TS is linked to a number of psychiatric disorders, including obsessive-compulsive disorder (63), and some patients with TS may present with symptoms of disability $(64,65)$. Standard medical treatment for TS does exist, including drug therapy and behavioral intervention (66). Even with the best psychotropic drug treatment and psychological behavioral therapy, only $1 / 3$ of patients receive complete relief; however, 30-40\% of patients experience exacerbations and $\sim 5 \%$ of patients develop disabilities $(66,67)$. Therefore, it is necessary to explore new therapies, including surgery, for patients whose condition is difficult to control. Researchers have previously attempted to perform nerve surgical resection in patients with TS with mixed success; the central tract complexus region in the thalamus was found to be the most effective target after different targets were attempted (68). Based on results for OCD and dyskinesia treatment, researchers have speculated that the internal segment of globus pallidus (GPI) and the VC/VS as DBS targets may also be effective at treating refractory TS (69).

The targeting of the thalamus DBS to treat TS has been suggested (70). An open-label study of 18 patients preliminarily reported positive results at 3- and 18-month follow-ups, and a 2-year evaluation indicated that the severity of spasms, obsessive-compulsive symptoms, anxiety and depression had decreased remarkably $(62,71)$. A case report also declared that DBS of the GPI and VC/VS may have potential curative effects in patients with severe TS (66). In 1999, Vandewalle et al (72) reported the case of a 42-year-old patient with intractable TS whose twitch symptom was eliminated 1 year following 


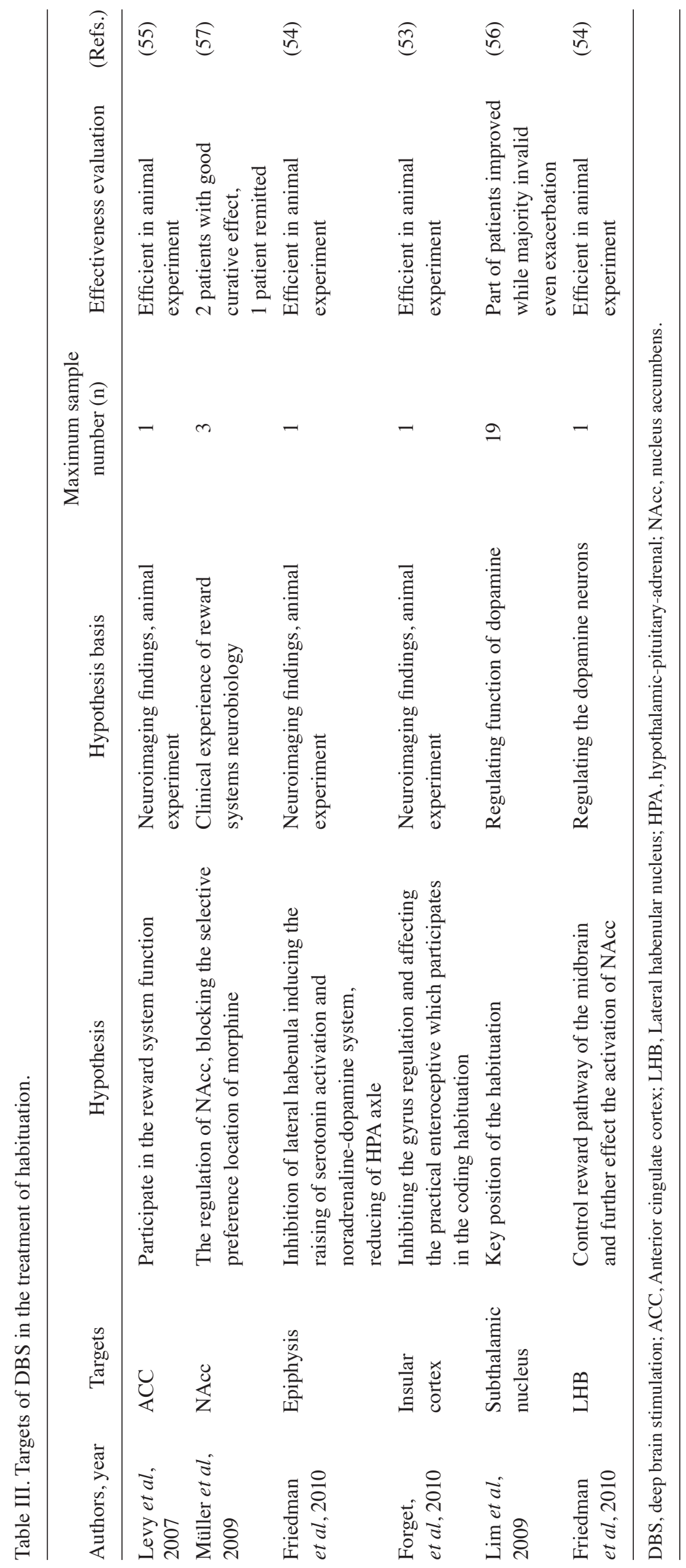


implantation of a double-sided electrode in the thalamic nuclei. In the 1960s, Hassler and Dieckmann (73) damaged the thalamic nuclei in 3 TS subjects; since then, considerable research has been conducted on the effectiveness of DBS treatment by implanting electrodes in the thalamic nuclei or other targets, such as the globus pallidus. These studies have reported significant improvements in twitch scores, although a proportion of patients experienced a variety of side effects, including energy loss, fatigue, lazy speech, less movement and decreasing libido $(38,74)$. However, the maximum sample size investigated thus far contained only 18 subjects and few randomized double-blind trials have been conducted $(62,75)$. The present evidence, however, is enough to support large-scale randomized clinical trials of DBS treatment for TS, with an aim to clarify the mechanism.

Targets of Alzheimer's disease (AD). AD is a neurodegenerative disease with a prevalence of $1-2 \%$ in America (76). More than $10 \%$ of people $>65$ years old have AD and the primary therapies available at present are drugs that slow down rather than prevent further cognitive decline (77). One case report described hyperamnesia in a patient with obesity treated with fornix DBS (76). Based on this report, Laxton et al (78) published a first phase clinical trial involving 6 elderly patients with AD who underwent DBS of the fornix. At a 1-year follow up, the glycometabolism in the parietal lobe brain had improved markedly. The potential mechanisms of this method are not yet clear; however, it is thought that activation of the fornix axon in turn activates the downstream brain regions involved in memory. In 2 patients who were examined using the simple mental symptoms scale (78), the speed of memory decline was demonstrated to have slowed down and a clinical improvement in symptoms was observed win no evident side effects. The effectiveness of this method of treatment for AD further supports the use of electric stimulation therapy as a treatment for neurodegenerative diseases including Parkinson's, AD, myodystonia, OCD, TS and depression.

Targets of $A N$. AN is an eating disorder that individuals experience to different extents, from being on a diet and deliberately inducing weight loss to deliberately and dramatically reducing body weight to far below healthy levels (79). The primary symptoms of AN are an excessive attention to weight and body image, intense fear of gaining weight, obsessive pursuit of thinness and significant reduction in weight. This is often combined with malnutrition, as well as metabolic and endocrine disorders, such as amenorrhea (80). AN can be a life-threatening condition due to excessive malnutrition, leading to cachexia and body failure. Morbidity rate of $\mathrm{AN}$ is between $5-15 \%$, with patients typically succumbing to cardiac complications, multiple organ failure, secondary infection or suicide (81-86).

Research into the targets of DBS to treat $\mathrm{AN}$ is in the animal experiment stage at present, and the primary experimental targets include the anterior hypothalamic nucleus (AHN) and NAcc (87).

Research involving low frequency electric excitement and electrolytic damage in canine and feline models identified that the AHN controls eating behavior and the metabolism of food in the body (88). A previous study has reported that the ventromedial hypothalamic nucleus (VMH) and lateral hypothalamic nucleus have an adverse function by which they can present opposite effects with electrical excitation or depolarization. Damage to the VMH induces overfeeding and obesity, whereas low frequency electrical stimulation results in reduced food intake (87). It is thought that countering this action with high frequency electrical stimulation may increase food intake to remedy $\mathrm{AN}$; however, the present research is only limited to animals (87).

Experimental data has also suggested that high-frequency DBS in the NAcc region may be an effective treatment for AN, OCD, depression and drug dependence (87). However, there are no related clinical experimental results at present (87).

\section{The side-effect of DBS}

Approximately 80,000 individuals have undergone DBS treatment worldwide, with a reported mortality rate of $0-0.4 \%$ (10). The side effects associated with DBS are categorized as acute side effects of surgery and long-term side effects.

Acute side effects of surgery. The acute side effects of surgery observed in large sample research studies include physical and mental side effects. Physical side effects include intracranial hemorrhage, which has a prevalence of $0.4-1.3 \%$ and irreversible brain damage, which has a prevalence of $0.8 \%$ (89). Furthermore, studies in patients who have undergone DBS have found that the prevalence of infection, epileptic seizure and cutaneous complications are $0.7,1.5$ and $25 \%$, respectively $(87,90,91)$.

One of the most harmful side effects of DBS is the risk of inducing psychiatric symptoms that differ from the therapy. Mental complications include transient aggressiveness, hypomania, mania, depression, anxiety, apathy and even suicide. The most common side effect is postoperative delirium (15.6\%), followed by depression and hypomania (92). For DBS treatment of Parkinson's disease, for example, the most severe side effect is an increased suicide risk, particularly when the target region is in the subthalamic nucleus and globus pallidus internus (87), with large sample research reporting a suicide risk of $0.16-0.32 \%$. It is therefore necessary to highlight the suicide risk screening of patients undergoing DBS.

Long-term side effects of surgery. A previous study has reported no serious side effects or pathological damage to other brain parenchymal tissue associated with the permanent implant, apart from cerebellar mass cell hyperplasia surrounding the electrode observed in the dissection results (93). Overall, an adverse outcome may result from a combination of mental, societal and operational factors (94). Issues with cognition have also been reported, most notably deficiencies of language fluency (95). It should be noted that there is currently no large-scale randomized blinded study data able to determine the long-term impacts of DBS on personality, cognitive function, attention and self-awareness. Overall, the side effects of DBS are much less prevalent and less serious than those of stereotactic surgery and there are fewer post-surgical complications associated with DBS. Furthermore, electrodes can be blocked to cease treatment if severe side effects manifest, to prevent further damage occurring. 


\section{Discussion}

DBS has some advantages compared with destructive and disruptive surgical techniques; however, the treatment process is slow and still requires invasive surgery. The popularization and application of DBS technology is impeded by the duration limit of the battery, regulation of stimulation parameters, selection of optimal target, patient selection criteria and ethical arguments. The exploitation of novel pharmacological agents and targets, more detailed local stimulation devices and extracranial neuromodulation devices within deeper brain structures (which are more effective than transcranial magnetic stimulation) (96), may lead to improvements in DBS technology. The development of other non-invasive effective intracranial targets, including visual purple and halorhodopsin neural circuit photosensitive manipulation, also deserve attention (96).

The aforementioned non-invasive techniques are unable to take the place of DBS. The tracer signal of the DBS electrode combined with a DBS imaging map depicts the evolutionary process of the temporal and spatial brain activities induced by DBS, which provides more information to improve the current research instruments and may lead to increased understanding of the basic pathological mechanisms of brain function (30) DBS is the only neurosurgical treatment method that can be controlled in a blinded study with the advantages of safety, adjustability and reversibility, thus providing a good method for investigating neurobiological mechanisms of mental disease (30).

The scope of DBS to treat mental illnesses may increase with in-depth knowledge of underlying pathological and physiological mechanisms, and the progress of imaging and hardware design technology. It should be emphasized that practitioners of DBS must adopt compulsory ethical standards, as well as exclusion and inclusion criteria, to prevent the practitioners from using this technology beyond the scope of its applications.

For DBS treatment of mental illnesses, optimal target exploration is the most important avenue of research. Current research indicates that there may exist one or more central targets for each mental disease based on different treatment principles (30). Furthermore, different syndromes and comorbidities may require different target combinations (97). To confirm the final potential central target, non-human primate models should be established according to the definition of refractory mental illness (98). Such a model should be selected based on the ability to imitate every psychotic symptom and pathological process entirely (97). Furthermore, a database should be established compiling the DBS therapeutic targets for every type of mental illness, including the mechanisms, stimulation parameters, curative effects, side effects and postoperative imaging results. Such a database may assist researchers from different institutions in matching suitable patients and treatments, and to rapidly share their study results.

In conclusion, a significant proportion of refractory psychopathic patients may greatly benefit from novel therapeutic methods. DBS treatment is an option that provides the ability to control the pathology of neural networks with an accurate and reversible treatment and promising curative effects have been reported. However, considerably more clinical data are required to eliminate basic ethical arguments and a universal standard should be established for patient and target selection. Overall, the application of DBS technology requires creative and adventurous exploration, as well as strict and objective standards.

\section{References}

1. Andrews JM and Nemeroff CB: Contemporary management of depression. Am J Med 97 (Suppl): 24S-32S, 1994.

2. Mann JJ: The medical management of depression. N Engl J Med 353: 1819-1834, 2005.

3. Murray CJ and Lopez AD: Global mortality, disability, and the contribution of risk factors: Global burden of disease study. Lancet 349: 1436-1442, 1997.

4. Yostos M and Murphy K: Investigation of the therapeutic applications, neuroanatomical targets and emerging technologies in deep brain stimulation surgery. BMC Proc 9 (Suppl 1): S1-S2, 2015.

5. Carver R,Lee WH, Kagarise BE, Hoo BA, Grace KP, Gleason PW and Halbert PC: Multiple configuration surgical cutting device, 2015.

6. Holtzheimer PE and Mayberg HS: Deep brain stimulation for psychiatric disorders. Annu Rev Neurosci 34: 289-307, 2011.

7. Benabid AL, Pollak P, Louveau A, Henry S and de Rougemont J: Combined (thalamotomy and stimulation) stereotactic surgery of the VIM thalamic nucleus for bilateral Parkinson disease. Appl Neurophysiol 50: 344-346, 1987.

8. Mallet L, Mesnage V, Houeto JL, Pelissolo A, Yelnik J, Behar C, Gargiulo M, Welter ML, Bonnet AM, Pillon B, et al: Compulsions, Parkinson's disease, and stimulation. Lancet 360: 1302-1304, 2002.

9. Mayberg HS, Lozano AM, Voon V, McNeely HE, Seminowicz D, Hamani C, Schwalb JM and Kennedy SH: Deep brain stimulation for treatment-resistant depression. Neuron 45: 651-660, 2005

10. Müller UJ, Voges J, Steiner J, Galazky I, Heinze HJ, Möller M, Pisapia J, Halpern C, Caplan A, Bogerts B and Kuhn J: Deep brain stimulation of the nucleus accumbens for the treatment of addiction. Ann N Y Acad Sci 1282: 119-128, 2013.

11. Schlaepfer TE, Frick C, Zobel A, Maier W, Heuser I, Bajbouj M, O'Keane V, Corcoran C, Adolfsson R, Trimble M, et al: Vagus nerve stimulation for depression: Efficacy and safety in a European study. Psychol Med 38: 651-661, 2008.

12. Chopra A, Klassen BT and Stead M: Current clinical application of deep-brain stimulation for essential tremor. Neuropsychiatr Dis Treat 9: 1859-1865, 2013.

13. Capelle HH and Krauss JK: Neuromodulation in dystonia: Current aspects of deep brain stimulation. Neuromodulation 12: 8-21, 2009.

14. Schlaepfer TE, Cohen MX, Frick C, Kosel M, Brodesser D, Axmacher N, Joe AY, Kreft M, Lenartz D and Sturm V: Deep brain stimulation to reward circuitry alleviates anhedonia in refractory major depression. Neuropsychopharmacology 33: 368-377, 2008.

15. Hardesty DE and Sackeim HA: Deep brain stimulation in movement and psychiatric disorders. Biol Psychiatry 61: 831-835, 2007.

16. McIntyre CC, Savasta M, Kerkerian-Le Goff L and Vitek JL: Uncovering the mechanism(s) of action of deep brain stimulation: Activation, inhibition, or both. Clin Neurophysiol 115: 1239-1248, 2004.

17. Beurrier C, Bioulac B, Audin J and Hammond C: High-frequency stimulation produces a transient blockade of voltage-gated currents in subthalamic neurons. J Neurophysiol 85: 1351-1356, 2001.

18. Zucker RS and Regehr WG: Short-term synaptic plasticity. Annu Rev Physiol 64: 355-405, 2002.

19. Dostrovsky JO, Levy R, Wu JP, Hutchison WD, Tasker RR and Lozano AM: Microstimulation-induced inhibition of neuronal firing in human globus pallidus. J Neurophysiol 84: 570-574, 2000 .

20. Jech R, Urgosík D, Tintera J, Nebuzelský A, Krásenský J,Liscák R, Roth $\mathrm{J}$ and Růzicka E: Functional magnetic resonance imaging during deep brain stimulation: A pilot study in four patients with Parkinson's disease. Mov Disord 16: 1126-1132, 2001.

21. McCracken CB and Grace AA: High-frequency deep brain stimulation of the nucleus accumbens region suppresses neuronal activity and selectively modulates afferent drive in rat orbitofrontal cortex in vivo. J Neurosci 27: 12601-12610, 2007. 
22. Vitek JL: Mechanisms of deep brain stimulation: Excitation or inhibition. Mov Disord 3 (Suppl 17): S69-S72, 2002.

23. Hilker R, Voges J, Thiel A, Ghaemi M, Herholz K, Sturm V and Heiss WD: Deep brain stimulation of the subthalamic nucleus versus levodopa challenge in Parkinson's disease: Measuring the on- and off-conditions with FDG-PET. J Neural Transm (Vienna) 109: 1257-1264, 2002.

24. Stefani A, Fedele E, Galati S, Raiteri M, Pepicelli O, Brusa L, Pierantozzi M, Peppe A, Pisani A, Gattoni G, et al: Deep brain stimulation in Parkinson's disease patients: Biochemical evidence. J Neural Transm Suppl: 401-408, 2006.

25. Kringelbach ML, Jenkinson N, Owen SL and Aziz TZ: Translational principles of deep brain stimulation. Nat Rev Neurosci 8: 623-635, 2007.

26. Schnitzler A and Gross J: Normal and pathological oscillatory communication in the brain. Nat Rev Neurosci 6: 285-296, 2005

27. Stefurak T, Mikulis D, Mayberg H, Lang AE, Hevenor S, Pahapill P, Saint-Cyr J and Lozano A: Deep brain stimulation for Parkinson's disease dissociates mood and motor circuits: A functional MRI case study. Mov Disord 18: 1508-1516, 2003

28. Sudhyadhom A, Haq IU, Foote KD, Okun MS and Bova FJ A high resolution and high contrast MRI for differentiation of subcortical structures for DBS targeting: The fast gray matter acquisition T1 inversion recovery (FGATIR). Neuroimage 2 (Suppl 47): T44-T52, 2009.

29. Wider C, Pollo C, Bloch J, Burkhard PR and Vingerhoets FJ: Long-term outcome of 50 consecutive Parkinson's disease patients treated with subthalamic deep brain stimulation. Parkinsonism Relat Disord 14: 114-119, 2008.

30. Schläpfer TE and Bewernick BH: Deep brain stimulation for psychiatric disorders-state of the art. Adv Tech Stand Neurosurg 34: 37-57, 2009.

31. Lozano AM, Mayberg HS, Giacobbe P, Hamani C, Craddock RC and Kennedy SH: Subcallosal cingulate gyrus deep brain stimulation for treatment-resistant depression. Biol Psychiatry 64: 461-467, 2008

32. Bewernick BH, Kayser S, Sturm V and Schlaepfer TE: Long-term effects of nucleus accumbens deep brain stimulation in treatment-resistant depression: Evidence for sustained efficacy. Neuropsychopharmacology 37: 1975-1985, 2012.

33. Montgomery SA and Asberg M: A new depression scale designed to be sensitive to change. Br J Psychiatry 134: 382-389, 1979.

34. Greenberg BD, Gabriels LA, Malone DA Jr, Rezai AR, Friehs GM, Okun MS, Shapira NA, Foote KD, Cosyns PR, Kubu CS, et al: Deep brain stimulation of the ventral internal capsule/ventral striatum for obsessive-compulsive disorder: Worldwide experience. Mol Psychiatry 15: 64-79, 2010.

35. Malone DA Jr, Dougherty DD, Rezai AR, Carpenter LL, Friehs GM, Eskandar EN, Rauch SL, Rasmussen SA, Machado AG, Kubu CS, et al: Deep brain stimulation of the ventral capsule/ventral striatum for treatment-resistant depression. Biol Psychiatry 65: 267-275, 2009.

36. Sartorius A and Henn FA: Deep brain stimulation of the lateral habenula in treatment resistant major depression. Med Hypotheses 69: 1305-1308, 2007.

37. Foltynie T and Hariz MI: Surgical management of Parkinson's disease. Expert Rev Neurother 10: 903-914, 2010.

38. Hamilton M: A rating scale for depression. J Neurol Neurosurg Psychiatry 23: 56-62, 1960

39. Jiménez F, Velasco F, Salin-Pascual R, Hernández JA, Velasco M, Criales JL and Nicolini H: A patient with a resistant major depression disorder treated with deep brain stimulation in the inferior thalamic peduncle. Neurosurgery 57: 585-593, 2005

40. Connolly KR and Thase ME: If at first you don't succeed: A review of the evidence for antidepressant augmentation, combination and switching strategies. Drugs 71: 43-64, 2011.

41. Greenberg BD, Malone DA, Friehs GM, Rezai AR, Kubu CS Malloy PF, Salloway SP, Okun MS, Goodman WK and Rasmussen SA: Three-year outcomes in deep brain stimulation for highly resistant obsessive-compulsive disorder. Neuropsychopharmacology 31: 2384-2393, 2006.

42. Abelson JL, Curtis GC, Sagher O, Albucher RC, Harrigan M, Taylor SF, Martis B and Giordani B: Deep brain stimulation for refractory obsessive-compulsive disorder. Biol Psychiatry 57: 510-516, 2005.

43. Anderson D and Ahmed A: Treatment of patients with intractable obsessive-compulsive disorder with anterior capsular stimulation. Case report. J Neurosurg 98: 1104-1108, 2003.
44. Gabriëls L, Cosyns P, Nuttin B, Demeulemeester H and Gybels J: Deep brain stimulation for treatment-refractory obsessive-compulsive disorder: Psychopathological and neuropsychological outcome in three cases. Acta Psychiatr Scand 107: 275-282, 2003

45. Nuttin B, Cosyns P, Demeulemeester H, Gybels J and Meyerson B: Electrical stimulation in anterior limbs of internal capsules in patients with obsessive-compulsive disorder. Lancet 354: 1526, 1999.

46. Nuttin BJ, Gabriëls LA, Cosyns PR, Meyerson BA, Andréewitch S, Sunaert SG, Maes AF, Dupont PJ, Gybels JM, Gielen F and Demeulemeester HG: Long-term electrical capsular stimulation in patients with obsessive-compulsive disorder. Neurosurgery 52 : 1263-1272; discussion 1272-1274, 2003.

47. Sturm V, Lenartz D, Koulousakis A, Treuer H, Herholz K, Klein JC and Klosterkötter J: The nucleus accumbens: A target for deep brain stimulation in obsessive-compulsive- and anxiety-disorders. J Chem Neuroanat 26: 293-299, 2003.

48. Fontaine D, Mattei V, Borg M, von Langsdorff D, Magnie MN, Chanalet S, Robert P and Paquis P: Effect of subthalamic nucleus stimulation on obsessive-compulsive disorder in a patient with Parkinson disease. Case report. J Neurosurg 100: 1084-1086, 2004.

49. Aouizerate B, Cuny E, Martin-Guehl C, Guehl D, Amieva H, Benazzouz A, Fabrigoule C, Allard M, Rougier A, Bioulac B, et al: Deep brain stimulation of the ventral caudate nucleus in the treatment of obsessive-compulsive disorder and major depression. Case report. J Neurosurg 101: 682-686, 2004.

50. Denys D, Mantione M, Figee $M$, van den Munckhof $P$, Koerselman F, Westenberg H, Bosch A and Schuurman R: Deep brain stimulation of the nucleus accumbens for treatment-refractory obsessive-compulsive disorder. Arch Gen Psychiatry 67: 1061-1068, 2010

51. Goodman WK, Foote KD, Greenberg BD, Ricciuti N, Bauer R, Ward H, Shapira NA, Wu SS, Hill CL, Rasmussen SA and Okun MS: Deep brain stimulation for intractable obsessive compulsive disorder: Pilot study using a blinded, staggered-onset design. Biol Psychiatry 67: 535-542, 2010.

52. Mallet L, Polosan M, Jaafari N, Baup N, Welter ML, Fontaine D, du Montcel ST, Yelnik J, Chéreau I, Arbus C, et al: Subthalamic nucleus stimulation in severe obsessive-compulsive disorder. $\mathrm{N}$ Engl J Med 359: 2121-2134, 2008.

53. Forget B, Pushparaj A and Le Foll B: Granular insular cortex inactivation as a novel therapeutic strategy for nicotine addiction. Biol Psychiatry 68: 265-271, 2010.

54. Friedman A, Lax E, Dikshtein Y, Abraham L, Flaumenhaft Y, Sudai E, Ben-Tzion M, Ami-Ad L, Yaka R and Yadid G: Electrical stimulation of the lateral habenula produces enduring inhibitory effect on cocaine seeking behavior. Neuropharmacology 59: 452-459, 2010

55. Levy D, Shabat-Simon M, Shalev U, Barnea-Ygael N, Cooper A and Zangen A: Repeated electrical stimulation of reward-related brain regions affects cocaine but not 'natural' reinforcement. J Neurosci 27: 14179-14189, 2007.

56. Lim SY, O'Sullivan SS, Kotschet K, Gallagher DA, Lacey C, Lawrence AD, Lees AJ, O'Sullivan DJ, Peppard RF, Rodrigues JP, et al: Dopamine dysregulation syndrome, impulse control disorders and punding after deep brain stimulation surgery for Parkinson's disease. J Clin Neurosci 16: 1148-1152, 2009.

57. Müller UJ, Sturm V, Voges J, Heinze HJ, Galazky I, Heldmann M, Scheich $\mathrm{H}$ and Bogerts B: Successful treatment of chronic resistant alcoholism by deep brain stimulation of nucleus accumbens: First experience with three cases. Pharmacopsychiatry 42: 288-291, 2009

58. Valencia-Alfonso CE, Luigjes J, Smolders R, Cohen MX, Levar N, Mazaheri A, van den Munckhof P, Schuurman PR, van den Brink W and Denys D: Effective deep brain stimulation in heroin addiction: A case report with complementary intracranial electroencephalogram. Biol Psychiatry 71: e35-e37, 2012.

59. Kuhn J, Gründler TO, Bauer R, Huff W, Fischer AG, Lenartz D, Maarouf M, Bührle C, Klosterkötter J, Ullsperger M and Sturm V: Successful deep brain stimulation of the nucleus accumbens in severe alcohol dependence is associated with changed performance monitoring. Addict Biol 16: 620-623, 2011.

60. Zhou H, Xu J and Jiang J: Deep brain stimulation of nucleus accumbens on heroin-seeking behaviors: A case report. Biol Psychiatry 69: e41-e42, 2011.

61. Kuhn J, Huff W, Lee SH, Lenartz D, Sturm V and Klosterkötter J: Deep brain stimulation in the treatment of psychiatric disorders. Fortschr der Neurol Psychiatr 75: 447-457, 2007. 
62. Servello D, Porta M, Sassi M, Brambilla A and Robertson MM Deep brain stimulation in 18 patients with severe Gilles de la Tourette syndrome refractory to treatment: The surgery and stimulation. J Neurol Neurosurg Psychiatry 79: 136-142, 2008.

63. Swain JE, Scahill L, Lombroso PJ, King RA and Leckman JF: Tourette syndrome and tic disorders: A decade of progress. J Am Acad Child Adolesc Psychiatry 46: 947-968, 2007.

64. Como PG: Neuropsychological function in Tourette syndrome. Adv Neurol 85: 103-111, 2001.

65. Mink JW, Walkup J, Frey KA, Como P, Cath D, Delong MR Erenberg G, Jankovic J, Juncos J, Leckman JF, et al: Patient selection and assessment recommendations for deep brain stimulation in Tourette syndrome. Mov Disord 21: 1831-1838, 2006.

66. Mink JW: Clinical review of DBS for tourette syndrome. Front Biosci (Elite Ed) 1: 72-76, 2009.

67. Zhang XH, Li YJ and Zhuang P: A study on outcome and mechanism of surgical treatment for Tourette's syndrome. Zhonghua Wai Ke Za Zhi 43: 608-611, 2005 (In Chinese)

68. Temel Y and Visser-Vandewalle V: Surgery in Tourette syndrome. Mov Disord 19: 3-14, 2004.

69. Dong S, Zhuang P, Zhang XH, Li JY and Li YJ: Unilateral deep brain stimulation of the right globus pallidus internus in patients with Tourette's syndrome: Two cases with outcomes after 1 year and a brief review of the literature. J Int Med Res 40: 2021-2028, 2012.

70. Plewnia C, Rzesnitzek L, Schober F, Soekadar S, Wächter T, Gharabaghi A and Krüger R: 171. Deep brain stimulation of the thalamus as a treatment of intractable Tourette syndrome. Clinical Neurophysiology 120: e72, 2009.

71. Porta M, Brambilla A, Cavanna AE, Servello D, Sassi M, Rickards H and Robertson MM: Thalamic deep brain stimulation for treatment-refractory Tourette syndrome: Two-year outcome. Neurology 73: 1375-1380, 2009.

72. Vandewalle V, van der Linden C, Groenewegen HJ and Caemaert J: Stereotactic treatment of Gilles de la Tourette syndrome by high frequency stimulation of thalamus. Lancet 353 724, 1999.

73. Hassler R and Dieckmann G: Stereotaxic treatment of tics and inarticulate cries or coprolalia considered as motor obsessional phenomena in Gilles de la Tourette's disease. Rev Neurol (Paris) 123: 89-100, 1970 (In French).

74. Houeto JL, Karachi C, Mallet L, Pillon B, Yelnik J, Mesnage V, Welter ML, Navarro S, Pelissolo A, Damier P, et al: Tourette's syndrome and deep brain stimulation. J Neurol Neurosurg Psychiatry 76: 992-995, 2005.

75. Welter ML, Mallet L, Houeto JL, Karachi C, Czernecki V, Cornu P, Navarro S, Pidoux B, Dormont D, Bardinet E, et al: Internal pallidal and thalamic stimulation in patients with Tourette syndrome. Arch Neurol 65: 952-957, 2008

76. Hamani C, McAndrews MP, Cohn M, Oh M, Zumsteg D, Shapiro CM, Wennberg RA and Lozano AM: Memory enhancement induced by hypothalamic/fornix deep brain stimulation. Ann Neurol 63: 119-123, 2008.

77. Burns A and Iliffe S: Alzheimer's disease. BMJ 338: b158, 2009

78. Laxton AW, Tang-Wai DF, McAndrews MP, Zumsteg D, Wennberg R, Keren R, Wherrett J, Naglie G, Hamani C, Smith GS and Lozano AM: A phase I trial of deep brain stimulation of memory circuits in Alzheimer's disease. Ann Neurol 68: $521-534,2010$.

79. Spaulding-Barclay MA, Stern J and Mehler PS: Cardiac changes in anorexia nervosa. Cardiol Young 26: 623-628, 2016.
80. Esposito R, Cieri F, di Giannantonio $\mathrm{M}$ and Tartaro A: The role of body image and self-perception in anorexia nervosa: The neuroimaging perspective. J Neuropsychol: 2016 May 25 (Epub ahead of print).

81. Ulger Z, Gürses D, Ozyurek AR, Arikan C, Levent E and Aydoğdu S: Follow-up of cardiac abnormalities in female adolescents with anorexia nervosa after refeeding. Acta Cardiol 61: 43-49, 2006.

82. Ravaldi C, Vannacci A and Ricca V: Cardiac complications of anorexia nervosa. Recenti Prog Med 94: 267-270, 2003 (In Italian).

83. McCallum K, Bermudez O, Ohlemeyer C, Tyson E, Portilla M and Ferdman B: How should the clinician evaluate and manage the cardiovascular complications of anorexia nervosa? Eat Disord 14: 73-80, 2006.

84. Steinhausen HC: The outcome of anorexia nervosa in the 20th century. Am J Psychiatry 159: 1284-1293, 2002.

85. Sullivan PF: Mortality in anorexia nervosa. Am J Psychiatry 152: 1073-1074, 1995

86. Katzman DK: Medical complications in adolescents with anorexia nervosa: A review of the literature. Int J Eat Disord 37 Suppl: S52-S59; discussion S87-S89, 2005.

87. Benabid AL and Torres N: New targets for DBS. Parkinsonism Relat Disord 1 (Suppl 18): S21-S23, 2012.

88. Kishi T and Elmquist JK: Body weight is regulated by the brain: A link between feeding and emotion. Mol Psychiatry 10: 132-146, 2005.

89. Remy C, Marret E and Bonnet F: Effects of acetaminophen on morphine side-effects and consumption after major surgery: Meta-analysis of randomized controlled trials. Br J Anaesth 94: 505-513, 2005.

90. Tykocki T, Mandat T, Kornakiewicz A, Koziara H and Nauman P: Deep brain stimulation for refractory epilepsy. Arch Med Sci 8: 805-816, 2012.

91. Voges J, Hilker R, Bötzel K, Kiening KL, Kloss M, Kupsch A, Schnitzler A, Schneider GH, Steude U, Deuschl G and Pinsker MO: Thirty days complication rate following surgery performed for deep-brain-stimulation. Mov Disord 22: $1486-1489,2007$

92. Houeto JL, Mesnage V, Mallet L, Pillon B, Gargiulo M, du Moncel ST, Bonnet AM, Pidoux B, Dormont D, Cornu P and Agid Y: Behavioural disorders, Parkinson's disease and subthalamic stimulation. J Neurol Neurosurg Psychiatry 72: 701-707, 2002.

93. DiLorenzo DJ, Jankovic J, Simpson RK, Takei H and Powell SZ: Long-term deep brain stimulation for essential tremor: 12-year clinicopathologic follow-up. Mov Disord 25: 232-238, 2010.

94. Schüpbach M, Gargiulo M, Welter ML, Mallet L, Béhar C, Houeto JL, Maltête D, Mesnage V and Agid Y: Neurosurgery in Parkinson disease: A distressed mind in a repaired body? Neurology 66: 1811-1816, 2006.

95. Saint-Cyr JA, Trépanier LL, Kumar R, Lozano AM and Lang AE: Neuropsychological consequences of chronic bilateral stimulation of the subthalamic nucleus in Parkinson's disease. Brain 123: 2091-2108, 2000.

96. Gradinaru V, Mogri M, Thompson KR, Henderson JM and Deisseroth K: Optical deconstruction of parkinsonian neural circuitry. Science 324: 354-359, 2009.

97. Goodman WK and Insel TR: Deep brain stimulation in psychiatry: Concentrating on the road ahead. Biol Psychiatry 65: 263-266, 2009

98. Holtzheimer PE and Mayberg HS: Stuck in a rut: Rethinking depression and its treatment. Trends Neurosci 34: 1-9, 2011. 